\title{
Research on the Development Countermeasures of Qingjiang Gallery based on the Life Cycle Theory
}

\author{
Xiaohui Shao ${ }^{\mathrm{a},}{ }^{*}$, Chun Liub \\ School of Management, Wuhan Industry and Business University, Wuhan 430065, China \\ azijian1206@qq.com, blc576@126.com
}

\begin{abstract}
Qingjiang Gallery is located in Changyang County of Hubei province, which is a national geological park in Hubei province, became the national AAAAA level scenic area in 2012 officially. In order to achieve the sustainable development, how to enhance the core competitiveness and how to attract more tourists are the main problems that Qingjiang Gallery should focus on. This paper tries to do a questionnaire survey, based on the Life Cycle Theory to analyze the status quo of Qingjiang Gallery scenic area, then try to propose some development countermeasures.
\end{abstract}

Keywords: Qingjiang Gallery, scenic area, life cycle, countermeasures.

\section{Introduction of the Research}

Based on life cycle of tourism scenic spot research is based on life cycle theory to analyze the practical situation of tourism destinations.

Through the case study Gray·R·Hovinen (1982) pointed out that the tourism development of Lancaster county has experienced five stages , thanks to its superior location and diversity of tourism resources the tourism destination has strong vitality, visitors won't have too big reduce in the long run [2].

Sheela Agarwal (2001) utilized Butzer's life-cycle theory of tourism destination and the modern theory of product restructuring to analyze the British seaside tourist destinations, He thought that the external factors contributed to the tourism market competition, internal factors lead to tourism destination competitiveness weakening, Recession continues to exist in the different stages of the evolution of tourism destination, restructuring tourism products can realize stable development of tourist destination, meanwhile he put forward some strategies, expand the research of tourism destination life cycle theory [3].

Liao Shichao (2006), Based on study of many scholars, Combined with years of tourist destination development practice in-depth analysis of the nature of the tourism destination life cycle and practice guidance for tourism destination development [4].

Zhang Qizhen (2004) In the direction of the sustainable development of scenic spots from the tourist environment capacity theory to analysis the influence of congestion scenic spot for tourists, Scenic area development in our country are pointed out three misunderstandings and then he puts forward the solutions and countermeasures for the sustainable development of scenic spots, to keep its scientific benign development [5].

LuXiaoBo (2015) According to the main contradiction and its evolution, Combined with the active model of tourist destination lifecycle, through literature analysis, survey and theoretical analysis our country 103 typical nature reserves' ecotourism stages, the nature reserve ecotourism were devided into five stages of development [6].

Wang Chunyu (2015) integrated with the tourism destination life cycle theory of knowledge, take the theory of tourism gaze theory as the support, did some researches on professional photography, amateur photography and the relationship between the formation and development of tourist destination [7].

Compared with foreign research, the researches on developing scenic area in China is still relatively backward, our schoolars are mainly concentrating on evaluating the tourism resources, protecting scenic areas and managing system of the relationship. 
The Qingjiang River Gallery is located in Changyang Tujia Ethnic Group Autonomous County of Yichang. It includes all the scenic spots between Geheyan Dam and Yanchi Spring along the Qingjiang River. It is a provincial-level scenic area and holiday resort in the Hubei province. It was founded in 2006, now becomes a national forest park. It, together with the ShenLongJjia, Wudang Mountain and Three Gorges of the Yangtze River are known as the Hubei four sacred tourist resources areas, listed as one of the top ten core scenic spots in the eco-cultural tourism circle of western Hubei .The annual reception capacity of it is more than 100millions, and it was awarded the standardization of services in Hubei Province Tourism Demonstration Spots. On December 19th, 2012, ChangYang Qingjiang Gallery in Yichang of central China's Hubei province was ranked as national AAAAA-class tourist scenic tourist resort. It is the demands of speeding up the development of the scenic area, promoting ecological cultural tourism industry's transformation, upgrading and meeting the objective demands of tourism strategic pillar industry, coping with the challenge of surrounding key scenic spots, the QingJiang River Gallery must take some important measures as the AAAAA scenic spots who wants to become bigger and stronger, conforming to the trend of tourism development [1].

In this paper, through the on-the-spot tourism resources investigation of Qingjiang Gallery, it evaluates the scenic area, the existing tourism products and its tourism markets. Besides, with the help of a tourism destination's life cycle theory, this paper hopes through qualitative and quantitative analysis to judge QingJiang River Gallery's stage of life cycle, based on this it tries to put forward some development strategies of the QingJiang Gallery. At present, tourism market competition is fierce, Qingjiang Gallery was just promoted to grade AAAAA tourist resort, and it faced a serious challenge. Since the Qingjiang Gallery has been established in 2006, it has always been very good development, especially after 2012, it realizes the development of blowout situation. In order to realize the sustainable utilization of resources and guarantee its developing trend, it is necessary to carry out the comprehensive analysis and research.

\section{The Empirical Research of Qingjiang Gallery}

\subsection{The Survey of Qingjiang Gallery Scenic Area}

The route of Qingjiang Gallery Cruise begins from Qingjiang Gallery Tourism Wharf to WuLuo Zhongli Mountains by boats with traditional Chinese characteristics. Boats pass by the Reflection Gorge, which is $5 \mathrm{~km}$ long with clear water and stiff cliff. The scenery is like painting pictures que along the both sides of it. The water surface here is flat like a mirror and the mountains abound is reflected on the water, that is why it got its name. Rocks on the both sides forms a unique natural stone forest landscape, which makes people lingering. Then, the boat will reach the Fairy Village a kilometer or so. There is a pleasant climate and picturesque view here. Step into the village, visitors can see rows of Tujia antique and amazing Stilted Building. There is a cave named Fairy Cave in this village and a strange stone is place in the cave, named ChangYang Stone. Walking around, visitors can see wild macaques playing on the trees and the people living here are mostly Tujia People. Back to the boat continuing the trip for about an hour tourists will arrive the terminal scenic spot "WuLuo Zhongli Mountains".

WuLuo Zhongli Mountains includes WuLuo Mount and Zhongli Mount. The mountains are about 300 meter high. It is $30 \mathrm{~km}$ away from the west of Longzhouping. The Mountains were the living life places of the Tujia leader Linjun, there is an extremely Tujia Stilted Building called White Tiger Hall, it was built to commemorate the ancestors by Tujia people. On the top of the mountain there is the Xiangwang Temple, which was built for commemorating the morality of Linjun. Stone God Platform, Ttujia people built it across to the temple to pray for many children, it represents the ancient Tujia people attach importance to the propagation of the race and family line. 


\subsection{Based on the Lifecycle Theory, Qingjiang Gallery's Development Research Empirical Analysis}

After researching on Qingjiang Gallery, we found the Reception Capacity designed of the scenic spot is so limited that a lot of infrastructure construction can't bear the great number of tourists' capacity now.

Due to national policy, when every "golden week" vacation is coming, a large number of tourists flocked to Qingjiang Gallery, but parking lot in scenic spot is so smaller, lacking of parking space, visitors can't find a parking place, which leads to the vehicle outside the scenic area can't get in , vehicle in the scenic area can't get out of it, numerous vehicles long queues formed, and chaotic scenes occurs. The chaos was caused by the lack of infrastructure in the scenic spot and the lack of scenic spot management skills. The staff has not set reasonable measures to prevent tourists from disorderly parking their vehicles, which caused the traffic jams in the scenic area.

The Cruise on Qingjiang Gallery Scenic Area, half of the journey was arranged on a ship, so managers should pay more attention to the public rest facilities and the supporting service facilities on the yacht. Since most of journey is on the boat, the majority of tourists will carry food with them, but there are only 2 trashcans on each cruise ship. Since our country is in a stage of rapid development, the populaces cultivation cannot reach the height as other developed countries, when people can't find a place to drop litter, they throw it into the Qingjiang River. But if the Qingjiang river was polluted, the galleries will fade away.

Another important component of Qingjiang gallery is Wuluo Zhongli Mountains. After 2 hours on the boat tourists will arrive at Wuluo Zhongli Mountains, everybody will get exciting, most visitors will immediately climbing the mountain, in the middle of the trip, with the fatigue slowly emerging and the sense of curiosity disappears gradually, some visitors will need to rest for a moment, but because of the poor design, too little rest area and the layout of rest area, which reduces the tourists' good experiences, made tourists unsatisfied with the scenic area.

People come to Qingjiang Gallery, is not only for sightseeing, but also want to know more about the local customs, self-experience is helpful. The professional narration is indispensable for a significant trip, but the narrator of Qingjiang Gallery are mostly locals, although they are very understanding the local conditions and customs, their professional qualities are on low level. Although they know a lot, they lack of professional training, service awareness, interpretation skills, etc. The service can't make the visitors have a good impression in their hearts on the scenic area. Following is a questionnaire on the Qingjiang Gallery (Figure 1 and table 1).

Table 1 The Tourists Numbers\& Tourism Income of Qingjiang Gallery

\begin{tabular}{|c|c|c|}
\hline Years & $\begin{array}{c}\text { Tourist Numbers } \\
\text { (ten thousands) }\end{array}$ & $\begin{array}{c}\text { Tourism income } \\
\text { (RMB ten thousands Yuan) }\end{array}$ \\
\hline 2006 & 9.83 & 1176 \\
\hline 2007 & 24.5 & 2940 \\
\hline 2008 & 30.64 & 3677 \\
\hline 2009 & 38.3 & 4597.4 \\
\hline 2010 & 47.89 & 5746.8 \\
\hline 2011 & 59.793 & 7174.8 \\
\hline 2012 & 71.753 & 8610 \\
\hline 2013 & 103.33 & 12399.6 \\
\hline
\end{tabular}




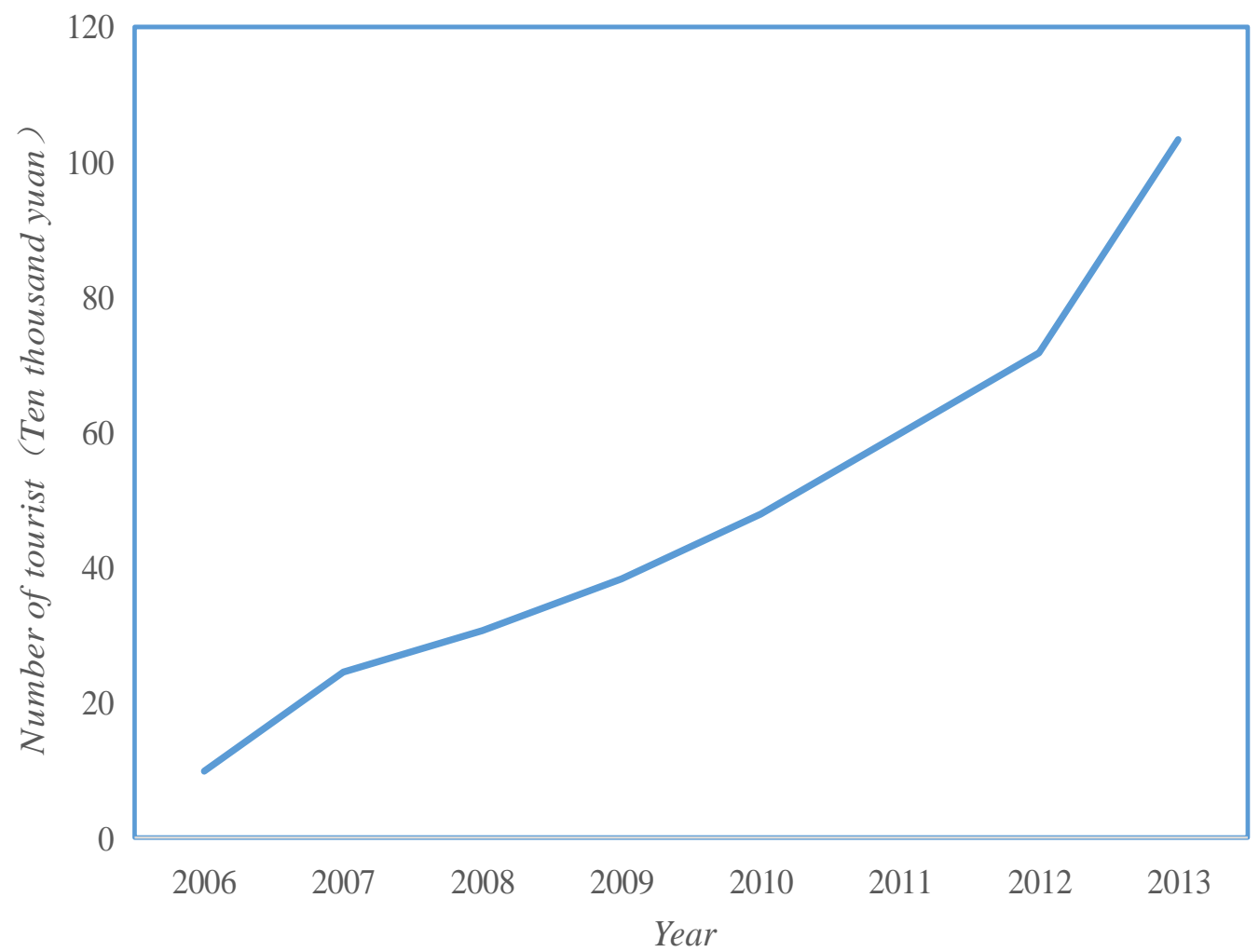

Fig. 1 Tourist Number and Income Line Chart (2006-2013)

According to current research data, based on the Life Cycle Theory, we can tell that the Qingjiang Gallery has transformed its life stage as following.

2006 to 2007 the Qingjiang Gallery was in its Exploration Stage. Tourist arrivals in 2006 only 98300 people, and tourism income of 2006 is 11.76 millions RMB. In 2007 the number slightly increased to 245000 , tourists and the tourism income is 29.4 millions RMB. Based on the tourism destination life cycle theory, the scenic spot belongs to the Exploration Stage, during this period, tourists of Qingjiang Gallery did not form a tourist flow. Because when it was just established, there has no basic facilities around it in Changyang County.

Compared with the previous two years, from 2008 to 2012 the tourists' arrivals improved markedly, the scenic spot went towards its Participation Stage with tourists' numbers increasing. During these years the local residents found business opportunities, humanistic service facilities began to rise, tourists number increased gradually. At this period, the local government began to fund for local road renovation.

Since 2012 the number of tourist boom, the tourist arrivals number of Qingjiang Galleries in 2013 reached 1.0333 millions and the tourists' income has reached 1.233996 billions Yuan. The scenic area formally entered the Stage of Developing, the government began to vigorously support the Qingjiang Gallery Scenic Area, investment, attract foreign capital, tourism service facilities were improved. The people's life style in the Scenic areas is also changed. As a result of the foreign capital injection, a complete set of scenic spot service facilities began to form and it upgraded the final success "gen AAAAA level scenic spot".

\subsection{The Empirical Analysis Based on Market Survey of Qingjiang Gallery Scenic Area}

200 copies of the tourist questionnaire were delivered in Qingjiang Gallery scenic spot, among them there are 186 copies effective questionnaire. 
2.3.1. Analysis on the Qingjiang Gallery scenic spot Tourist Market

Table 2 Tourist Market Analysis

\begin{tabular}{|c|c|c|c|c|}
\hline Source of Tourists & frequency & percentage & Effective percentage & cumulative percentage \\
\hline Jiangsu & 5 & 2.7 & 2.7 & 2.7 \\
\hline Chongqing & 1 & 0.5 & 0.5 & 3.2 \\
\hline Hubei & 127 & 68.3 & 68.3 & 71.5 \\
\hline Henan & 5 & 2.7 & 2.7 & 74.2 \\
\hline Shanghai & 6 & 3.2 & 3.2 & 87.4 \\
\hline Jiangxi & 6 & 3.2 & 3.2 & 82.8 \\
\hline Guangdong & 4 & 2.2 & 2.2 & 87.1 \\
\hline Hunan & 8 & 4.3 & 4.3 & 89.8 \\
\hline Guangxi & 5 & 2.7 & 2.7 & 90.3 \\
\hline Liaoling & 1 & 0.5 & 0.5 & 91.4 \\
\hline Shangdong & 2 & 1.1 & 1.1 & 93.5 \\
\hline Hebei & 4 & 2.2 & 2.2 & 94.6 \\
\hline Sichuan & 2 & 1.1 & 1.1 & 95.7 \\
\hline Shanxi & 2 & 1.1 & 1.1 & 96.8 \\
\hline Beijing & 2 & 1.1 & 1.1 & 97.8 \\
\hline Heilongjiang & 2 & 1.1 & 1.1 & 98.4 \\
\hline Jilin & 1 & 0.5 & 0.5 & 100 \\
\hline Zhejiang & 2 & 1.1 & 1.1 & \\
\hline Qinghai & 1 & 0.5 & 0.5 & \\
\hline total & 186 & 100 & 100 & \\
\hline
\end{tabular}

According Table 2, there are 68.3\% tourists of Qingiiang Gallery's Tourist Market coming from Hubei province, $4.3 \%$ from Hunan province, 3.2\% from Shanghai province and 3.2\% from Jiangxi province .This suggests that the Qingjiang Gallery is famous for its scenic area only in its own province and neighbor provinces. It will take some time to spread its fame to open the domestic tourists market. It can also be explained that the distance is also affect tourists to choose tourist destination, visitors near Hubei province, the transportation is convenient, the tourists intend to high, so most of the visitors come from Hubei, Hunan, Jiangxi, Although Shanghai is far from Hubei province relative to other provinces, the traffic is very convenient.

\subsubsection{Analysis on the Qingjiang Gallery scenic spot Tourists' Sex \& Marriage}

Table 3 Sex Analysis Statement

\begin{tabular}{|c|c|c|c|c|c|}
\hline \multicolumn{2}{|c|}{} & frequency & percentage & Effective percentage & cumulative percentage \\
\hline \multirow{3}{*}{ Effective } & Female & 112 & 60.2 & 60.2 & 60.2 \\
\cline { 2 - 6 } & male & 74 & 39.8 & 39.8 & 100.0 \\
\cline { 2 - 6 } & total & 186 & 100.0 & 100.0 & \\
\hline
\end{tabular}

Table 3 reveals that female visitors in Qingjiang Gallery accounts for $60.2 \%$, that is $20 \%$ higher than male visitors. Since Qingjiang gallery is beautiful as a scroll of landscape painting, and the whole journey can be done on cruise ship, which belongs to a Leisure and Sightseeing Tour, the only period that requires some physical strength is climbing Wuluo Zhongli Mountains, but the county is located in the middle and lower reaches of the Yangtze river, so mountains here is low, the female tourists is fully capable to cover it. While most of male tourists don't like the leisure tourism because of the lower tourist experience. Above is the reason why the Qingjiang Gallery Scenic Spot has a higher percentage of female tourists.

Table 4 Tourists Marriage Analysis

\begin{tabular}{|c|c|c|c|c|c|}
\hline \multicolumn{2}{|c|}{} & frequency & percentage & Effective percentage & cumulative percentage \\
\hline \multirow{3}{*}{ Effective } & married & 108 & 58.1 & 58.1 & 58.1 \\
\cline { 2 - 6 } & Single & 78 & 41.9 & 41.9 & 100.0 \\
\cline { 2 - 6 } & total & 186 & 100.0 & 100.0 & \\
\hline
\end{tabular}


From table 4, Married tourists occupies $58.1 \%$ of the number, which is $16.2 \%$ higher than single tourists. This illustrates the Qingjiang Gallery is more popular in married visitors. And most of the visitors are coming with their children, they want to make their children feeling great by enjoying the fresh air in the beautiful environment far away from the crowed and noisy city. The family came to relax, enjoy the beautiful scenery. The unmarried tourists are relatively young, they come to seeking fresh tourist destination. In order to enhance the core competition, Qingjiang Gallery can focus on designing and innovating more parent-child projects in the scenic area, which can attract more tourists with good experiences, even it can make the tourists revisit the Scenic Area again and again.

\subsubsection{Analysis the tourists' Age of Qingjiang Gallery Scenic Area}

Figure 2 is the Tourists' Age Analysis Diagram, it reveals that tourists age distribution .There are73 in the 186 tourists which accounts for $39.2 \%$ of the total belongs to the ages from 18 to 26 years old, and people from 27 to 40 years old accounts for $29 \%$ of the total, while under the age of 18 and over 60 years old visitors accounts for only $3.8 \%$ and $2.7 \%$ respectively. It is clear that most of the tourists in Qingjiang gallery are young adults, because they have enough money and leisure time to go out for a tour. And a person under the age of 18, due to the restriction of academic, payment ability, a few tourists of this age groups come to the scenic area. Similarly, visitors over the age of 60 , though they are not lack money, because of the limitation of body conditions, the tourists number of this age is also a few.

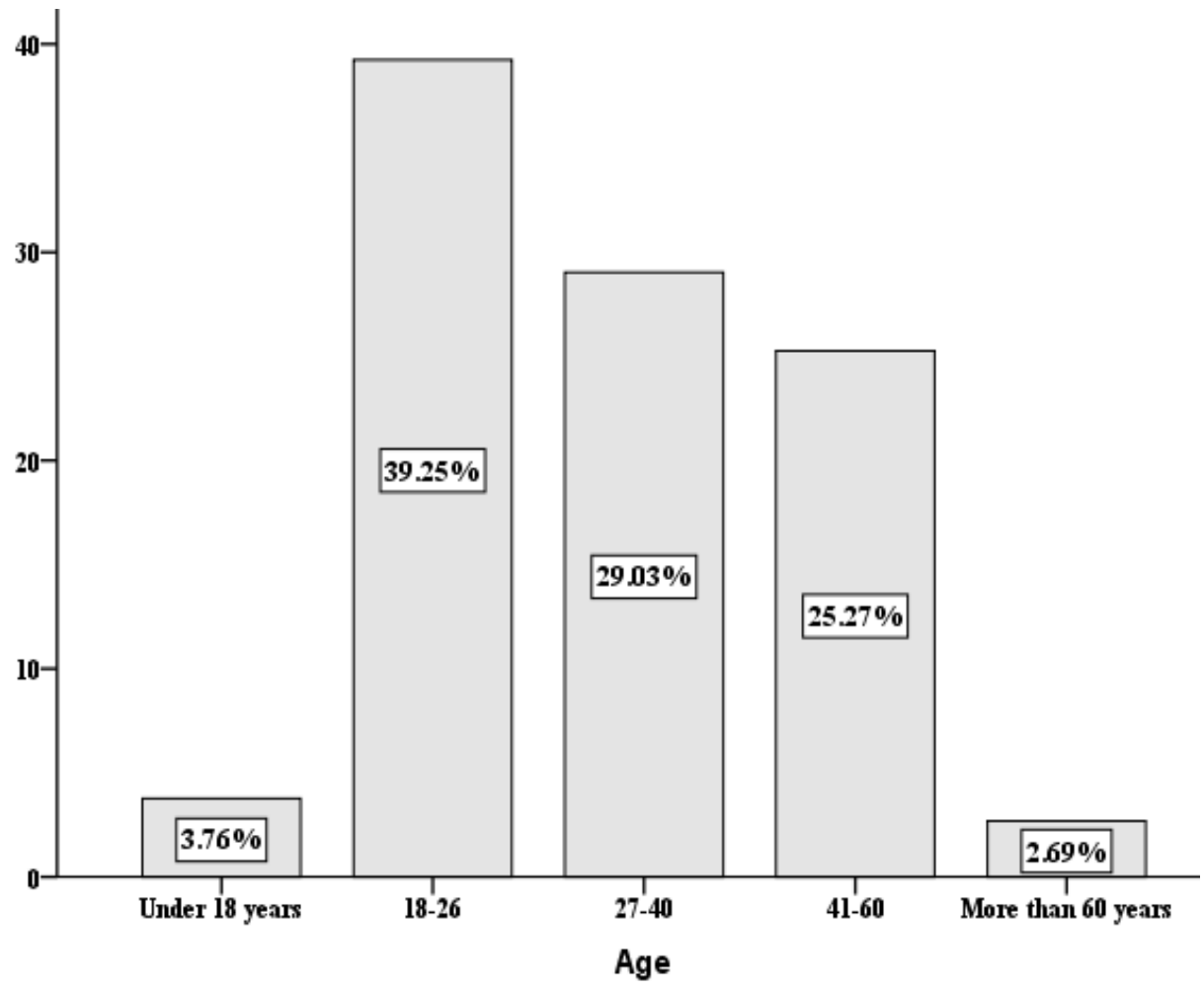

Fig. 2 Tourists’ Age Analysis Diagram

Table 5 Tourists' Education Level

\begin{tabular}{|c|c|c|c|c|c|}
\hline \multicolumn{2}{|c|}{} & frequency & percentage & $\begin{array}{c}\text { Effective } \\
\text { percentage }\end{array}$ & $\begin{array}{c}\text { cumulative } \\
\text { percentage }\end{array}$ \\
\hline \multirow{4}{*}{ effective } & $\begin{array}{c}\text { Under primary high } \\
\text { school }\end{array}$ & 13 & 7.0 & 7.0 & 7.0 \\
\cline { 2 - 5 } & $\begin{array}{c}\text { Vocational /High School } \\
\text { Education }\end{array}$ & 56 & 30.1 & 30.1 & 37.1 \\
\cline { 2 - 6 } & junior college & 40 & 21.5 & 21.5 & 58.6 \\
\cline { 2 - 6 } & Bachelor & 63 & 33.9 & 33.9 & 92.5 \\
\cline { 2 - 6 } & Master's and above & 14 & 7.5 & 7.5 & 100.0 \\
\hline
\end{tabular}


Table 5 shows, among 186 people, there are $33.9 \%$ of people with bachelor's degree, $30.1 \%$ of the people have high school or technical secondary school degree, another $21.5 \%$ of them own a college degree. Maybe the people who has master degree and above or under primary high school degree are busy in studies, which makes the people has less time than other levels to visit the scenic area .

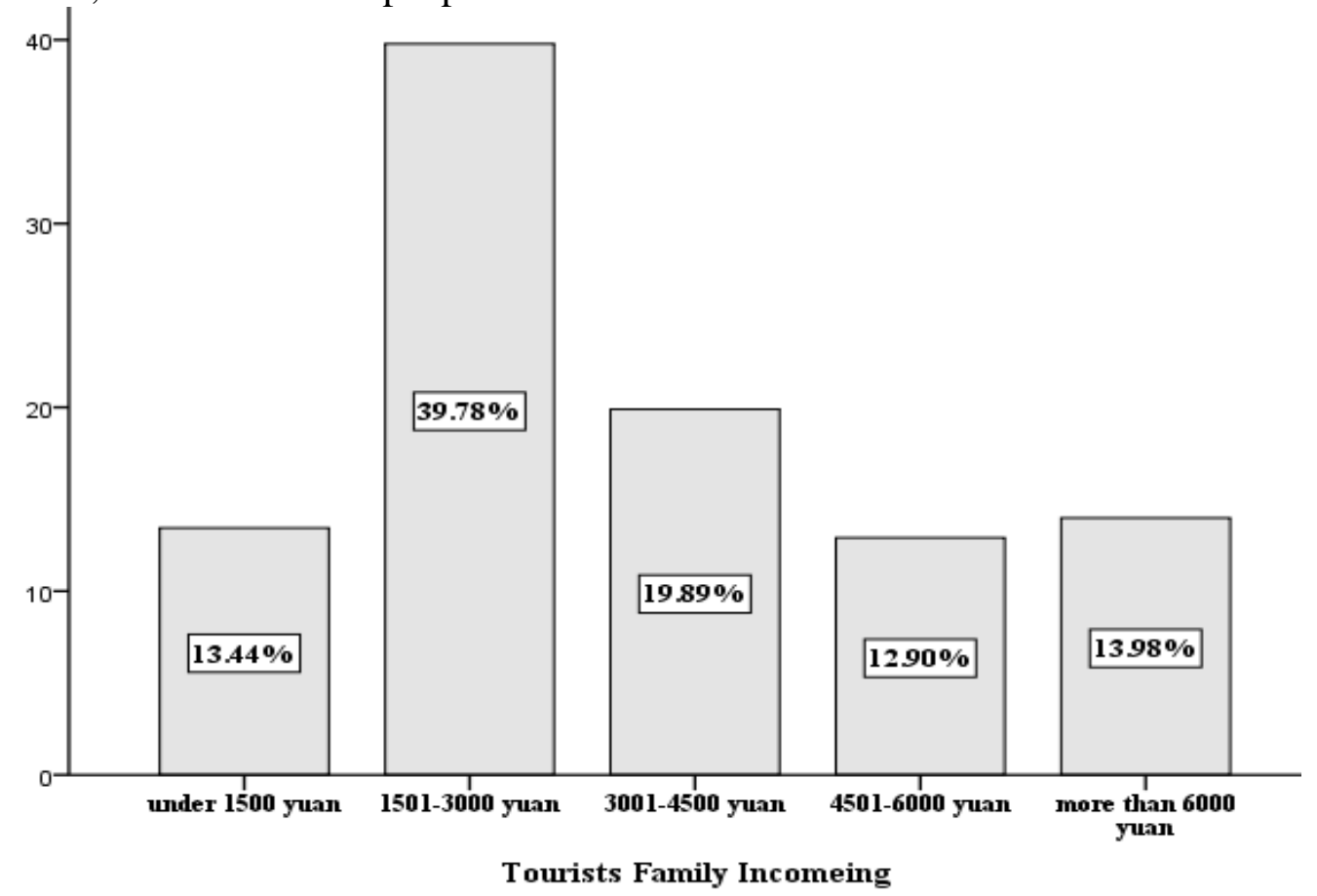

Fig. 3 Tourists Family Income

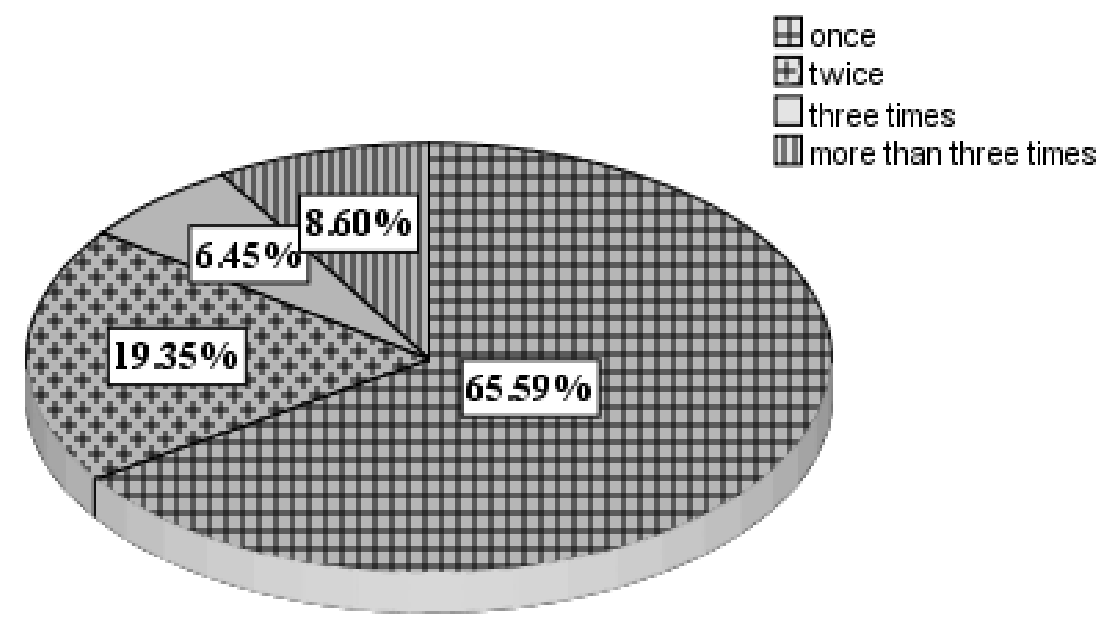

Fig. 4 Travel Frequency Diagram

From Figure 3, it can be seen from the perspective of family income, among 186 families, there are 74 families which belongs to the income phase of 1501-3000 RMB ,it takes $39.8 \%$ of the total. There are 26 families' monthly income more than $6000 \mathrm{RMB}$, and family monthly income less than 1500 RMB is 25 families, which showed that with the development of the society, more and more people will go out to travel for relaxing, people would like to paid more money for a higher quality of life. Families which monthly earned 1501-3000RMB accounted for $40 \%$ of the total tourists' families, suggesting that families to Qingjiang Gallery Scenic Area are mostly belongs to this stage. Through the result, we can suggest the scenic spot should explore more activities and reasonable price for families of this stage to meet their consumption needs, make their journey more memorable.

From figure 4 the Travel Frequency Diagram, there are 122 persons among 186, accounted for $65.6 \%$ of the total, this group of people visited the Qingjiang Gallery for the first time. This is the second visiting to the Qingjiang Gallery accounted for 36 people, 19.4\% of the total visitors. Third 
visiting tourists accounted for only 6.5\%, which indicates that the revisiting rate of Qingjiang Gallery is low. Revisit rate not only for Qingjiang Gallery, but for each scenic spot is very important, it is rated as the lifeline for each scenic spot. If the revisiting rate is too low, the development of the scenic area will be affected. At present the main problems of Qingjiang Gallery are the following: tourists come to visit just for sightseeing, tourists experience is too little, tourists' participation is not strong, etc. With time flies, above questions will became a very serious problem, which needs to be solved effectively and rapidly. Increasing tourists' participation, improving the quality of service, develop some new tourism projects with characteristic of Tujia nationality, which will attract more tourists, let visitors feel that it is worth visiting Qingjiang Gallery, make visitors feel comfortable, so as to make the Qingjiang Gallery enters the stable development stage.

The questionnaires of Qingjiang Gallery Tourist Satisfaction are designed for each factor a few questions, and the answers to these questions designed five dimensions, they are: strongly disagree, disagree, in general, agree, and with very much agree. Which can be determined based on the satisfaction of the respondents for each of the factors.

Table 6 Qingjiang Gallery scenic spot's Tourist Satisfaction

\begin{tabular}{|c|c|c|c|c|c|}
\hline & $\begin{array}{c}\text { strongly } \\
\text { disagree }\end{array}$ & disagree & in general & Agreed & $\begin{array}{c}\text { Totally } \\
\text { agreed }\end{array}$ \\
\hline B13.1 fascinating landscape & $20 / 10.8$ & $9 / 4.8$ & $36 / 19.4$ & $81 / 43.5$ & $40 / 21.5$ \\
\hline B13.2 Landscape protection degree & $14 / 7.5$ & $7 / 3.8$ & $47 / 25.3$ & $75 / 40.3$ & $43 / 23.1$ \\
\hline B13.3 traffic order & $12 / 6.5$ & $10 / 5.4$ & $33 / 17.7$ & $84 / 45.2$ & $47 / 25.3$ \\
\hline B13.4 Local residents' attitude & $7 / 3.8$ & $11 / 5.9$ & $33 / 17.7$ & $80 / 43$ & $55 / 29.6$ \\
\hline B13.5 service attitude & $7 / 3.8$ & $7 / 3.8$ & $36 / 19.4$ & $79 / 42.5$ & $57 / 30.6$ \\
\hline B13.6 life convenience convenience & $6 / 3.2$ & $13 / 7.0$ & $50 / 26.9$ & $67 / 36.0$ & $50 / 26.9$ \\
\hline B13.7 Landscape features & $8 / 4.3$ & $16 / 8.6$ & $50 / 26.9$ & $70 / 37.6$ & $42 / 22.6$ \\
\hline B13.8 condition of accommodation & $8 / 4.3$ & $17 / 9.1$ & $50 / 26.9$ & $68 / 36.6$ & $43 / 23.1$ \\
\hline B13.9 Infrastructure facilities & $9 / 4.8$ & $18 / 9.7$ & $55 / 29.6$ & $59 / 31.7$ & $45 / 24.2$ \\
\hline B13.10 Guide's personnel service & $3 / 1.6$ & $9 / 4.8$ & $29 / 15.6$ & $85 / 45.7$ & $60 / 32.3$ \\
\hline attitude & $6 / 3.2$ & $8 / 4.3$ & $51 / 27.4$ & $78 / 41.9$ & $43 / 23.1$ \\
\hline B13.11 scenic area management & $7 / 3.8$ & $11 / 5.9$ & $50 / 26.9$ & $80 / 43.0$ & $38 / 20.4$ \\
\hline B13.12 dining environment & $9 / 4.8$ & $9 / 4.8$ & $55 / 29.6$ & $72 / 38.7$ & $41 / 22.0$ \\
\hline B13.13 complaints handling & $11 / 5.9$ & $12 / 6.5$ & $42 / 22.6$ & $75 / 40.3$ & $46 / 24.7$ \\
\hline B13.14 Bad atmosphere in society & $3 / 1.6$ & $12 / 6.5$ & $43 / 23.1$ & $70 / 37.6$ & $58 / 31.2$ \\
\hline B13.15 Tourism consumption & $3 / 1.6$ & $13 / 7.0$ & $54 / 29.0$ & $74 / 39.8$ & $42 / 22.6$ \\
\hline willingness & $9 / 4.8$ & $13 / 7.0$ & $48 / 25.8$ & $72 / 38.7$ & $44 / 23.7$ \\
\hline B13.16 Price & $11 / 5.9$ & $11 / 5.9$ & $48 / 25.8$ & $70 / 37.6$ & $46 / 24.7$ \\
\hline B13.17 Scenic attraction & $9 / 4.8$ & $14 / 7.5$ & $64 / 34.4$ & $59 / 31.7$ & $40 / 21.5$ \\
\hline B13.18 participation degree & $11 / 5.9$ & $11 / 5.9$ & $48 / 25.8$ & $70 / 37.6$ & $46 / 24.7$ \\
\hline B13.19 Attractions for updates & $10 / 5.4$ & $6 / 3.2$ & $35 / 18.8$ & $83 / 44.6$ & $52 / 28.0$ \\
\hline B13.21 Degree of crowdedness & & & & & \\
\hline
\end{tabular}

Table 6 comes from the comprehensive survey of visitors in Qingjiang Gallery. The survey covers 21 aspects of it. It is a comprehensive physical examination that allows us to fully understand the advantages and disadvantages of it. Qingjiang Gallery has showed its own features: 65\% tourists agreed that the scenery in the scenic spot is very attractive. $72.6 \%$ of visitors satisfied with the attitudes of local residents, and $68.8 \%$ of the visitors said that they were willing to spend on Qingjiang Gallery. There are $72.6 \%$ of visitors thought they had good impressions of the gallery. But the passengers are all very dissatisfied with the chaos, crowded people and vehicles, Attractions' updating is limited in Qingjiang Gallery Scenic Area, which is also a question we should solve during the development stage of the scenic spot. As a new AAAAA level scenic area, the tourism infrastructure and the tourist satisfaction are in good situation. 


\section{The Development Countermeasures for Qingjiang Gallery Scenic Area}

\section{(a) Strengthen propaganda, enhance the brand image.}

Most visitors of Qingjiang Gallery Scenic Area comes from Hubei. Although it has tourists out of Hubei, but the number of its percentage is very limited, so to strengthen the propaganda, enhance the brand image by spreading advertisement through the Local TV stations and China Central Television (CCTV) is in need .

(b) Innovate tourism projects, stimulate the tourists to participate in.

When developing and designing the new tourism projects, it is important to avoid making repetitive tourist experience, we need to add the original ecological Tujia culture characteristics to form its own characteristic landscape, through the new tourism projects, the visitors can understand Tujia's history and culture, which can attract more tourists and win their satisfactions.

(c) Perfect supporting facilities, improve the quality of service

On abroad due to social development, people pay more attention to the service, and respect the experience of tourists. But in domestic scenic spot is more concerned about how to improve the efficiency, improve the supporting facilities of scenic spots, make stars' service standards, training employees to make sure that the employee offer more excellent service, make tourists linger.

(d) Complete Qingjiang Gallery Scenic Area's management system, balance the interests reasonably

Qingjiang Gallery is invested by Wuhan Venture Capital firms, ChangYang County Government and Qingjiang Scenic Area, they joint management the scenic area. While insisting on the management rules and regulations, balance the interests reasonably a standard management of the scenic spots should be built for balance the interests reasonably. We need pay more attentions to cultivate the quality education of the employees, strengthen employee training plan. The Scenic Area and the government joint management coordinate with each other, try to be a union to ensure the sustainable and healthy development of the scenic spot.

\section{Acknowledgments}

This work was financially supported by Hubei province tourism development committee 2015 Annual Research Project (2015006) \& Wuhan Industry and Business University Annual Research project (A2013005) fund.

\section{References}

[1] Changyang Tujia Autonomous County Tourism Bureau. Changyang Tujia Autonomous County Tourism Industry Development Planning (2011-2025) [EB/OL]. [2015-04-07] (2012-07-31), http://www.cytour.gov.cn/ghzs/Print.asp?ArticleID=784

[2] Gary R.Hovinen, Visitor Cycles Outlook for Tourism in Lancaster County, J, Annals of Tourism Research.1982, 9:565-583;

[3] Sheela. Agarwal, Restructuring Seaside tourism-The Resort Life cycle, J, Annals of Tourism Research.2001, 29 (1): 25-55;

[4] Liao Shichao, The essence of the tourism destination life cycle analysis and application, J, Journal of Commercial Age, 2006 (18): 81-82

[5] Zhang Qizhen, Tourism environmental capacity for tourism sustainable development, J, The influence of Anyang normal college journal, 2004 (4): 137-139.

[6] LuXiaoBo. Chen xiao-ying. Guo Di, Based on the theory of paradoxes and tourist destination life cycle stages of nature reserve ecotourism development in China, J, Journal of Arid Zone Resources and Environment, 2015, 29 (3): 188-192.

[7] Wang Chunyu, The relationship between the photography and tourism destination life cycle, J, Journal of Travel Survey, 2015 (4): 53. 